Tropical Journal of Pharmaceutical Research February 2020; 19 (2): 401-409

ISSN: $1596-5996$ (print); 1596-9827 (electronic)

(c) Pharmacotherapy Group, Faculty of Pharmacy, University of Benin, Benin City, 300001 Nigeria.

\title{
Perception and satisfaction of stakeholders regarding the patient care area pharmacist initiative in a military hospital in Saudi Arabia
}

\author{
Mohammed Almzeiny ${ }^{1}$, Fowad M Khurshid ${ }^{2}$, Nadeen L Alaneazi ${ }^{3}$, Suhoud S \\ Alotaibi ${ }^{3}$, Sara N Alharbi ${ }^{3}$, Ali A Almitwazi ${ }^{1}$, Ali M Alkhodair ${ }^{1}$, Fahad AlKharji ${ }^{1}$, \\ Hussain A Alomar ${ }^{2}$, Mohammed S Alsultan ${ }^{2}$ \\ ${ }^{1}$ Department of Pharmacy, Prince Sultan Military Medical City, Riyadh, ${ }^{2}$ Department of Clinical Pharmacy, College of \\ Pharmacy, King Saud University, PO Box 2457, Riyadh 11451, ${ }^{3}$ College of Pharmacy, Princess Nourah Bint Abdulrahman \\ University, Riyadh, Saudi Arabia
}

*For correspondence: Email: almuzaini@psmmc.med.sa; Tel: +966-55061-6000

Sent for review: 18 September 2019

Revised accepted: 26 January 2020

\begin{abstract}
Purpose: To explore the perceptions and satisfaction of stakeholders (physicians, nurses, and pharmacists) regarding services provided by the patient care area pharmacist (PCAP) initiative.

Methods: This was a cross-sectional study conducted at Prince Sultan Military Medical City (PSMMC). The questionnaire was hand-delivered to a random sample of stakeholder groups (including physicians, nurses, and pharmacists) in three different areas of the hospital: the neonatal intensive care unit (NICU), high dependency unit (HDU), and pediatric nephrology. The questionnaire consisted of three sections. The first section collected demographic information of the participants, and the other sections collected anonymous opinions regarding services provided by the PCAP.

Results: Ninety-nine participants, comprising physicians ( $n=27 ; 27.27 \%)$, nurses ( $n=55 ; 55.55 \%)$, inpatient pharmacists $(n=13 ; 13.13 \%)$, and PCAPs $(n=4 ; 4.04 \%)$, participated in the survey. $A$ majority of the respondents (92.3\%) were satisfied with the PCAP services, and all respondents recommended expansion of the PCAP service to cover all wards.

Conclusion: The findings show that all participants have a positive perception of the PCAP service; PCAPs were seen by the participants as drug experts, and their recommendations were perceived as clinically relevant. All stakeholders sought to continue working with the PCAP.
\end{abstract}

Keywords: Patient care, PCAP, Attitude, Satisfaction, Pharmacy

This is an Open Access article that uses a fund-ing model which does not charge readers or their institutions for access and distributed under the terms of the Creative Commons Attribution License (http://creativecommons.org/licenses/by/4.0) and the Budapest Open Access Initiative (http://www.budapestopenaccessinitiative.org/read), which permit unrestricted use, distribution, and reproduction in any medium, provided the original work is properly credited.

Tropical Journal of Pharmaceutical Research is indexed by Science Citation Index (SciSearch), Scopus, International Pharmaceutical Abstract, Chemical Abstracts, Embase, Index Copernicus, EBSCO, African Index Medicus, JournalSeek, Journal Citation Reports/Science Edition, Directory of Open Access Journals (DOAJ), African Journal Online, Bioline International, Open-J-Gate and Pharmacy Abstracts

\section{INTRODUCTION}

Pharmacists not only dispense medications; they also provide a number of clinical pharmacy services [1], that do much to prevent patients from experiencing serious side effects or adverse drug events (ADEs) that lead to admission to hospital with its corresponding financial implications [2]. The pharmacist therefore plays an important role in maintaining patient safety 
and ensuring that medications are used correctly to produce the best possible health outcomes [3].

In the previous literature, a number of systematic reviews have reported favorably on the quality of care that pharmacists provide to patients $[2,4,5]$. One such study of an inpatient care setting conducted by Kaboli et al found that the quality of care was enhanced when a clinical pharmacist was involved [2]. Similarly, Koshman et al strongly recommended making clinical pharmacists a standard member of heart failure care teams [4], while Chisholm-Burns et al inferred from the benefits to direct patient care that they discovered that pharmacists should form a key part of every healthcare team [5].

The role of the pharmacist is to liaise with patients and other healthcare professionals to ensure that the most appropriate medications are used to produce the best possible patient outcomes [6]. Prince Sultan Military Medical City (PSMMC) operates a pharmacy practice model that divides pharmacists into two discrete groups-"clinical" and "distribution"-that serve entirely different functions. Distribution pharmacists focus on dispensing drugs to inpatients and have very few clinical responsibilities, while clinical pharmacists are responsible for the clinical services side and have hardly anything to do with the dispensary.

It is crucial for hospital pharmacy departments to maintain the support of their stakeholders; therefore, they must regularly canvass those stakeholders' opinions on the quality of services being offered and endeavor to implement any recommendations for improvement. With this in mind, the present study investigated how the stakeholders perceive the current patient care area pharmacist (PCAP) services, how satisfied they are with them, and how far they consider that they have an impact on the quality of patient care provided in terms of optimized medications distribution and use in communicative partnership with other healthcare professionals. The aim is that the results of this study will contribute to improving further the quality of pharmaceutical services at PSMMC.

\section{METHODS}

\section{Study design}

A cross-sectional questionnaire-based study was conducted at PSMMC, a 1,350-bed tertiary care referral hospital for members of the Saudi Arabian armed forces and their families. PSMMC is in Riyadh, Saudi Arabia; it is operated by and reports to the Medical Services Department
(MSD) of the Ministry of Defense (MOD), Saudi Arabia.

The questionnaire, which was written in English, was distributed along with a cover letter explaining the survey's objectives and assuring participants that their involvement would be voluntary and their identities would remain anonymous.

\section{Participants}

A random sample of stakeholders-physicians, nurses, and pharmacists-was selected from across three different hospital departments-the neonatal intensive care unit (NICU), the high dependency unit (HDU), and pediatric nephrology - that were chosen based on how busy, complex, and in need of service improvement they are. The selected participants were given the questionnaire by hand and asked to return it, when completed, directly to either the survey coordinator or the pharmacy department.

\section{Survey development}

The study investigators performed a literature search to identify whether any similar study had validated instruments that could be repurposed for use here. However, as no suitable instrument was found to meet the objectives of the present study, a new questionnaire was devised to capture stakeholders' perceptions of and satisfaction with the current PCAP services provision. The questionnaire was divided into three sections, to capture the participants' demographic information, opinions about the PCAP services, and perceptions of those clinical, distributive, and communication services' impact on quality.

Each questionnaire section contained a set of statements; for each statement, respondents were asked to self-report their agreement level on a five-point Likert scale ( 1 = strongly agree; 2 $=$ tend to agree; $3=$ neither agree nor disagree; 4 $=$ tend to disagree, and $5=$ strongly disagree). With the help of five physicians, seven nurses, and three pharmacists, a pilot study was conducted to verify the questionnaire's content and validity; this led to just minor tweaks of some questions to improve their clarity. Any information collected via the pilot study was excluded from the main study.

Not only was this study conducted in accordance with both the Declaration of Helsinki [7] and the guidelines for Good Clinical Practice [8], but, prior to initiation of the study, approval was also 
received from PSMMC's Research Ethics Committee (ref no. HAP-01-R-015).

\section{Statistical analysis}

Data computation and analysis were conducted using Statistical Package for Social Sciences for Windows, version 12 (SPSS Inc, Chicago, Illinois). Stakeholder demographics and responses were analyzed using descriptive statistics before being tabulated as mean values, standard deviations, frequencies, and percentages.

\section{RESULTS}

\section{Response rate and respondent demographics}

In total, 99 questionnaires were distributed to the stakeholder groups during the study period. All distributed questionnaires were returned to the research team. Of these, $13(13.13 \%)$ were completed by in-patient pharmacists, $4(4.04 \%)$ by PCAPs, $27(27.27 \%)$ by physicians, and 55 $(55.55 \%)$ by nurses (Table 1$)$.

\section{Physicians' perception and level of satisfaction with PCAP}

The demographic information of the participating physicians is presented in Table 1. Twenty-seven physicians responded to the survey; however, responses were not supplied for all survey items. Almost half $(48.2 \%)$ of physicians had worked at the hospital for more than 5 years. The current job positions of the responding physicians included consultant (22.2 \%), registrar (29.6\%), and resident $(40.7 \%)$.

Table 1: Stakeholders' characteristics
The responses regarding the physicians' perceptions of PCAPs in terms of enhancing communication, clinical, and distributive services are shown in Table 2 and Table 3 . The majority of physicians (96\%) agreed that PCAP practitioners were available and cooperative when required. In addition, the respondents stated that they received reliable, detailed, and accurate information on a daily basis from PCAPs; only 12 $\%$ faced barriers when communicating with PCAPs. In addition, physicians displayed a high level of comfort in sharing information on therapeutic care plans and drug selection with PCAPs and the presence of a PCAP on the ward accelerated their work. The majority of the respondents $(92.3 \%)$ agreed that PCAPs suggested changes to drug therapy regimens when necessary owing to their knowledge of alternative medications, and $72 \%$ of participating physicians said that PCAPs could perform therapeutic drug monitoring (TDM) and provide advice to physicians on therapy options. The majority $(92.3 \%)$ agreed that the availability of a PCAP would improve patient outcomes and the quality of patient care.

When asked to assess their satisfaction with pharmacists within a patient care area, $92.3 \%$ of the physicians were satisfied with the PCAP services and all of the responding physicians recommended that the PCAP initiative should be expanded to cover all wards.

\section{Nurses' perception and level of satisfaction with PCAP}

The demographic information of the participating nurses is presented in Table 1. Fifty-five nurses responded to the survey; however, responses were not supplied for all survey items.

\begin{tabular}{lcccc}
\hline Parameter & $\begin{array}{c}\text { Inpatient } \\
\text { pharmacist } \\
\mathbf{N = 1 3}\end{array}$ & $\begin{array}{c}\text { Patient care area } \\
\text { pharmacist } \\
\mathbf{N = 4}\end{array}$ & $\begin{array}{c}\text { Physician } \\
\mathbf{N = 2 7}\end{array}$ & $\begin{array}{c}\text { Nurse } \\
\mathbf{N = 5 5}\end{array}$ \\
\hline Gender & 5 & 1 & 14 & - \\
Male & 5 & 3 & 13 & 55 \\
Female & 8 & 1 & 01 & 04 \\
Experience (years) & 2 & - & 10 & 22 \\
$0-1$ & 4 & 2 & 03 & 09 \\
$2-3$ & 5 & 1 & 03 & 05 \\
$4-5$ & 1 & - & 10 & 15 \\
$6-9$ & 1 & 2 & 22 & - \\
$\geq 10$ & 13 & 1 & - & 55 \\
Area of practice & - & 1 & 5 & - \\
Neonatal ICU & - & &
\end{tabular}

$\mathbf{N}=$ total respondents 
Table 2: Physicians' perceptions about the impact of PCAP in terms of enhancing communication with other health care professionals

\begin{tabular}{|c|c|c|c|c|}
\hline \multirow[t]{2}{*}{ Survey item } & \multicolumn{3}{|c|}{ Percentage (\%) of physicians who } & \multirow[t]{2}{*}{$\mathrm{N}^{\star}$} \\
\hline & $\begin{array}{l}\text { Strongly } \\
\text { agree/Tend } \\
\text { to agree }\end{array}$ & $\begin{array}{l}\text { Neither } \\
\text { agree nor } \\
\text { disagree }\end{array}$ & $\begin{array}{l}\text { Strongly } \\
\text { disagree/ } \\
\text { tend to } \\
\text { disagree }\end{array}$ & \\
\hline \multicolumn{5}{|l|}{ Communication } \\
\hline PCAP showed respect toward me & 96.2 & 3.8 & 0 & 26 \\
\hline PCAP members were available when I need & 96.2 & 3.8 & 0 & 25 \\
\hline PCAP was cooperative when I must communicate & 96.2 & 3.8 & 0 & 26 \\
\hline $\begin{array}{l}\text { PCAP enhance my communication with the pharmacy } \\
\text { because I have to deal with one pharmacist }\end{array}$ & 88.5 & 11.5 & 0 & 26 \\
\hline $\begin{array}{l}\text { I receive the information I need from PCAP in a timely } \\
\text { manner }\end{array}$ & 92.3 & 7.7 & 0 & 26 \\
\hline $\begin{array}{l}\text { The information I receive from PCAP on daily basis is } \\
\text { detailed and accurate }\end{array}$ & 96.0 & 4.0 & 0 & 25 \\
\hline I receive reliable information from PCAP & 96.0 & 4.0 & 0 & 25 \\
\hline I feel comfortable sharing information with PCAP & 96.0 & 4.0 & 0 & 25 \\
\hline $\begin{array}{l}\text { I get most of the day-to-day information I need from PCAP } \\
\text { by E-mail }\end{array}$ & 37.5 & 20.8 & 41.7 & 24 \\
\hline $\begin{array}{l}\text { I get most of the day-to-day information I need from PCAP } \\
\text { by phone }\end{array}$ & 48.0 & 36.0 & 16.0 & 25 \\
\hline $\begin{array}{l}\text { PCAP is located in the ward, it is easy to reach him/her } \\
\text { when I need him her }\end{array}$ & 88.5 & 7.7 & 3.8 & 26 \\
\hline I face many barriers when I communicate with PCAP & 12.0 & 0 & 88.0 & 25 \\
\hline $\begin{array}{l}\text { The availability of PCAP in my ward make the information } \\
\text { that I need such as availability of medications which } \\
\text { accelerated my work }\end{array}$ & 96.0 & 4.0 & 0 & 25 \\
\hline
\end{tabular}

${ }^{*}$ Not all participants responded to all questions, $N=$ Total respondents; PCAP: patient care area pharmacist

The majority $(94.5 \%)$ of respondent nurses held a Bachelor's degree in nursing. Approximately twothirds $(63.6 \%)$ of the nurses had worked at PSMMC for less than 5 years. The current job positions of the responding nurses included staff nurse-2 (76.4\%), staff nurse-1 (9.1\%), and nursing team leader (14.5\%).

The responses regarding the nurses' perceptions of PCAP in terms of enhancing communication and clinical services are shown in Table 4 and Table 5.

The majority of nurses (94\%) agreed that PCAP practitioners simplified communication with the pharmacy and that the PCAP answered all inquiries relating to medications. In addition, nurses stated that they received reliable, detailed, and accurate information on patient's medication regimen in a timely manner on daily basis from PCAPs; only $18 \%$ faced barriers when communicating with PCAPs. In addition, nurses displayed a high level of comfort $(87.3 \%)$ in sharing information with PCAPs and the placement of a PCAP in the ward made them easy to reach.

Most of the respondents (96.2\%) agreed that PCAPs helped them to check the appropriateness of the drug dose, advised about the compatibility, stability, and storage of intravenous medications
(94.3\%), explained how to use drugs (92.3\%), and advised about the preparation and administration of medicines (90.6\%). In addition, a large number of nurses $(84.6 \%)$ said that the care that patients received from a PCAP is unique, and approximately $90.6 \%$ of them agreed that the availability of a PCAP would improve patient outcomes and the quality of patient care.

When asked to assess their satisfaction with pharmacist within a patient care area, $90.6 \%$ of the responding nurses were satisfied with PCAP services and recommended the expansion of the PCAP services to cover all nursing stations.

\section{Pharmacists' perception of PCAP}

The demographic information of the participating pharmacists is presented in Table 1. Thirteen pharmacists responded to the survey. More than half $(53.8 \%)$ of the responding pharmacists had a Bachelor's degree in pharmacy and approximately $38.5 \%$ had a Doctor of Pharmacy (PharmD) degree. The majority (84.6\%) of pharmacists had worked at PSMMC for fewer than 5 years.

The responses regarding the pharmacists' perceptions of PCAPs in terms of enhancing communication and clinical services are shown in Table 6. 
Table 3: Physicians' perceptions about the impact of PCAP in terms of enhancing clinical, and distributive services with other health care professionals

\begin{tabular}{lll}
\hline $\begin{array}{l}\text { Strongly } \\
\text { agree/Tend } \\
\text { to agree }\end{array}$ & $\begin{array}{l}\text { Neither } \\
\text { agree nor } \\
\text { disagree }\end{array}$ & $\begin{array}{l}\text { Strongly } \\
\text { disagree/ } \\
\text { tend to } \\
\text { disagree }\end{array}$ \\
\hline
\end{tabular}

\section{Clinical}

PCAP suggest change in drug therapy when necessary

PCAP has positively affected my decision

PCAP Actively participate in bedside discussions to assist clinicians on therapeutic care plans and drug selection

PCAP helps in establishing guidelines

PCAP performs therapeutic drug monitoring and advise clinicians on therapy options

PCAP can monitor patient response to drug therapy from

toxicity/side effects perspective

PCAP can monitor patient response to drug therapy from an

effectiveness perspective

PCAP check drug-drug interactions

PCAP check if the medications are contraindication

PCAP check if the drug needs to dose adjustment e.g. renal or hepatic

PCAP participate in dose calculation for patients

PCAP can improve patient outcome/quality of patient care

PCAP play an important role in physicians' education especially resident

PCAP play important role in patient counseling in discharge

PCAP enhances patients' appreciation and satisfaction

\begin{tabular}{|c|c|c|c|}
\hline 92.3 & 7.7 & 0 & 26 \\
\hline 88.5 & 11.5 & 0 & 26 \\
\hline 84.6 & 11.5 & 3.9 & 26 \\
\hline 69.2 & 26.9 & 3.9 & 26 \\
\hline 72.0 & 24.0 & 4.0 & 25 \\
\hline 76.0 & 16.0 & 8.0 & 25 \\
\hline 72.0 & 16.0 & 12.0 & 25 \\
\hline 80.8 & 11.5 & 7.7 & 26 \\
\hline 88.5 & 7.7 & 3.8 & 26 \\
\hline 80.8 & 15.4 & 3.8 & 26 \\
\hline 84.6 & 15.4 & 0 & 26 \\
\hline 92.3 & 7.7 & 0 & 26 \\
\hline 73.1 & 26.9 & 0 & 26 \\
\hline 57.7 & 34.6 & 7.7 & 26 \\
\hline 61.5 & 34.6 & 3.8 & 26 \\
\hline 96.2 & 3.8 & 0 & 26 \\
\hline 92.3 & 7.7 & 0 & 26 \\
\hline 88.5 & 11.5 & 0 & 26 \\
\hline 96.2 & 3.8 & 0 & 26 \\
\hline 88.5 & 11.5 & 0 & 26 \\
\hline 92.3 & 7.7 & 0 & 6 \\
\hline 100.0 & 0 & 0 & \\
\hline
\end{tabular}

\section{Distributive}

PCAP knew about hospital formulary and non-formulary medications

PCAP knew about alternative of medications

PCAP provides timely information on drug availability and out of

stock medications

PCAP help in facilitating drug availability

PCAP help in accelerating drug availability through drug profiling

inside the ward

I am satisfied towards PCAP services

I recommend expanding the PCAP services to cover all wards

0

Table 4: Nurses perceptions about the impact of PCAP in term of enhancing communication

\begin{tabular}{|c|c|c|c|c|}
\hline \multirow[t]{2}{*}{ Survey item } & \multicolumn{3}{|c|}{ Percentage (\%) of nurses who } & \multirow[t]{2}{*}{$\mathrm{N}^{*}$} \\
\hline & $\begin{array}{l}\text { Strongly } \\
\text { agree/Tend } \\
\text { to agree }\end{array}$ & $\begin{array}{l}\text { Neither } \\
\text { agree nor } \\
\text { disagree }\end{array}$ & $\begin{array}{l}\text { Strongly } \\
\text { disagree/ } \\
\text { tend to } \\
\text { disagree }\end{array}$ & \\
\hline PCAP is available when I need any assistant & 89.1 & 10.9 & 0 & 55 \\
\hline PCAP ease the communication with pharmacy & 94.4 & 5.6 & 0 & 54 \\
\hline PCAP answers all inquiries in regard to medications & 94.5 & 5.5 & 0 & 55 \\
\hline I receive the information I need from PCAP in a timely manner & 90.9 & 9.1 & 0 & 55 \\
\hline $\begin{array}{l}\text { The information I receive from PCAP in daily basis is detailed and } \\
\text { accurate }\end{array}$ & 92.7 & 5.5 & 1.8 & 55 \\
\hline I receive reliable information from PCAP & 94.5 & 3.6 & 1.8 & 55 \\
\hline I feel comfortable sharing information with PCAP & 87.3 & 9.1 & 3.6 & 55 \\
\hline I get most of the day-to-day information I need from PCAP by E-mail & 36.2 & 25.5 & 38.3 & 47 \\
\hline I get most of the day-to-day information I need from PCAP by phone & 60.9 & 21.7 & 17.4 & 46 \\
\hline PCAP is located in the ward, therefore it is easy to reach him/her & 89.1 & 7.3 & 3.6 & 55 \\
\hline I face many barriers when I communicate with PCAP & 18.2 & 9.1 & 72.7 & 55 \\
\hline $\begin{array}{l}\text { I am often delayed in my job because I do not have the information I } \\
\text { need }\end{array}$ & 16.4 & 14.5 & 69.1 & 55 \\
\hline PCAP showed respect toward me & 92.7 & 7.3 & 0 & 55 \\
\hline
\end{tabular}


Table 5: Nurses perceptions about the impact of PCAP in term of enhancing clinical services

\begin{tabular}{|c|c|c|c|c|}
\hline \multirow[t]{2}{*}{ Survey item } & \multicolumn{3}{|c|}{ Percentage (\%) of nurses who } & \multirow[t]{2}{*}{$\mathrm{N}^{*}$} \\
\hline & $\begin{array}{l}\text { Strongly } \\
\text { agree/Tend } \\
\text { to agree }\end{array}$ & $\begin{array}{l}\text { Neither } \\
\text { agree nor } \\
\text { disagree }\end{array}$ & $\begin{array}{l}\text { Strongly } \\
\text { disagree/ } \\
\text { tend to } \\
\text { disagree }\end{array}$ & \\
\hline PCAP explained how to use drugs & 92.3 & 5.7 & 1.9 & 53 \\
\hline $\begin{array}{l}\text { PCAP has increased patient understanding of their medication } \\
\text { regimen }\end{array}$ & 84.6 & 13.5 & 1.9 & 52 \\
\hline $\begin{array}{l}\text { PCAP give advice to me about the preparation and administration } \\
\text { of medicines }\end{array}$ & 90.6 & 5.7 & 3.7 & 53 \\
\hline $\begin{array}{l}\text { PCAP give advice to me about compatibility, stability, and storage } \\
\text { of IV medications }\end{array}$ & 94.3 & 3.8 & 1.9 & 53 \\
\hline PCAP help me to check the appropriateness of dose of medication & 96.2 & 1.9 & 1.9 & 53 \\
\hline PCAP follow up patients' status & 83.0 & 11.3 & 5.7 & 53 \\
\hline PCAP play an important role in patient counseling on discharge & 67.3 & 23.1 & 9.6 & 52 \\
\hline The care that patient receive from PCAP is unique & 84.6 & 11.5 & 3.8 & 52 \\
\hline PCAP can improve overall patient outcome/quality of patient care & 90.6 & 7.5 & 1.9 & 53 \\
\hline $\begin{array}{l}\text { PCAP knew about hospital formulary and non-formulary } \\
\text { medications }\end{array}$ & 96.2 & 3.8 & 0 & 52 \\
\hline PCAP knew about alternative of medications & 92.5 & 7.5 & 0 & 53 \\
\hline I am satisfied with the service from PCAP & 90.6 & 7.5 & 1.9 & 53 \\
\hline I recommend expanding the PCAP services to cover all nurse & 90.6 & 9.4 & 0 & 53 \\
\hline
\end{tabular}

${ }^{\star}$ Not all participants responded to all questions, $N=$ Total respondents; PCAP: patient care area pharmacist

Table 6: Pharmacists' perceptions of the impact of PCAP in term of enhancing the communication, clinical, and distributive services

\begin{tabular}{|c|c|c|c|c|}
\hline \multirow[t]{2}{*}{ Survey item } & \multicolumn{3}{|c|}{ Percentage (\%) of pharmacists who } & \multirow[t]{2}{*}{$\mathrm{N}^{*}$} \\
\hline & $\begin{array}{l}\text { Strongly } \\
\text { agree/Tend } \\
\text { to agree }\end{array}$ & $\begin{array}{l}\text { Neither } \\
\text { agree nor } \\
\text { disagree }\end{array}$ & $\begin{array}{l}\text { Strongly } \\
\text { disagree/ } \\
\text { tend to } \\
\text { disagree }\end{array}$ & \\
\hline PCAP member was available when required & 76.9 & 7.7 & 15.4 & 13 \\
\hline $\begin{array}{l}\text { PCAP enhance your communication with physicians and nurses } \\
\text { because you have to deal with one person }\end{array}$ & 92.3 & 7.7 & 0 & 13 \\
\hline PCAP showed respect toward you & 92.3 & 7.7 & 0 & 13 \\
\hline PCAP suggest change on drug therapy when necessary & 92.3 & 7.7 & 0 & 13 \\
\hline PCAP established guidelines & 84.6 & 7.7 & 7.7 & 13 \\
\hline $\begin{array}{l}\text { PCAP performs therapeutic drug monitoring and advise medical staff } \\
\text { on therapy options }\end{array}$ & 92.3 & 7.7 & 0 & 13 \\
\hline $\begin{array}{l}\text { PCAP can monitor patient response to drug therapy from toxicity/side } \\
\text { effects perspective }\end{array}$ & 69.2 & 23.1 & 7.7 & 13 \\
\hline $\begin{array}{l}\text { PCAP can monitor patient response to drug therapy from an } \\
\text { effectiveness perspective }\end{array}$ & 84.6 & 7.7 & 7.7 & 13 \\
\hline PCAP check drug-drug interactions & 76.9 & 23.1 & 0 & 13 \\
\hline PCAP check if the medications are contraindication & 69.2 & 23.1 & 7.7 & 13 \\
\hline PCAP check if the drug need dose adjustment & 92.3 & 7.7 & 0 & 13 \\
\hline PCAP participate in dose calculation for patients & 100.0 & 0 & 0 & 13 \\
\hline $\begin{array}{l}\text { PCAP actively participates in bedside discussions to assist clinicians } \\
\text { on therapeutic care plans and drug selection }\end{array}$ & 53.8 & 46.2 & 0 & 13 \\
\hline PCAP can improve patient outcome/quality of patient care & 92.3 & 7.7 & 0 & 13 \\
\hline PCAP enhances patients' appreciation and satisfaction & 84.6 & 7.7 & 7.7 & 13 \\
\hline PCAP knew about hospital formulary and non-formulary medications & 100.0 & 0 & 0 & 13 \\
\hline PCAP knew about alternative medications & 92.3 & 7.7 & 0 & 13 \\
\hline $\begin{array}{l}\text { PCAP provides timely information on drug availability and out of } \\
\text { Stock medication for his/her team }\end{array}$ & 84.6 & 7.7 & 7.7 & 13 \\
\hline Working shift was easy for me to compare with PCAP shift & 46.2 & 15.3 & 38.5 & 13 \\
\hline My work schedule is more flexible than PCAP & 38.4 & 30.8 & 30.8 & 13 \\
\hline PCAP help pharmacists by decreasing workload & 92.3 & 0 & 7.7 & 13 \\
\hline PCAP help pharmacists by solving raised problems & 84.6 & 15.4 & 0 & 13 \\
\hline
\end{tabular}


The majority of the respondents $(92.3 \%)$ agreed that PCAP suggested changes to drug therapy regimens when necessary owing to their knowledge of alternative medications, could perform TDM and advise medical staff on therapy options, to check if the drug dose required adjustment, and help pharmacists by decreasing workload. The majority of respondents stated that the availability of a PCAP would improve patient outcomes and the quality of patient care. In addition, a large number of the responding pharmacists $(84.6 \%)$ believed that a PCAP could monitor patient response to drug therapy from an effectiveness perspective, enhance patients' appreciation and satisfaction, establish guidelines, and help pharmacists by solving raised problems.

\section{Satisfaction regarding PCAP}

Of the four PCAPs who responded, all agreed or strongly agreed that the restructuring of services, by the participation in decentralized clinical activities, improved job satisfaction, and that other healthcare professionals valued their contribution to patient care, and that patient safety was improved.

\section{DISCUSSION}

As far as the authors are aware, following an extensive literature search, this is one of the first studies to investigate stakeholders' perceptions of pharmacists' involvement in and impact on patient care areas in a military hospital in Saudi Arabia. Understanding how stakeholders rate the PCAP service is crucial for facilitating its further uptake and implementation. To this end, study participants were asked to describe their experience of the pharmaceutical service indepth, particularly how they view pharmacists' contributions to the work of hospital wards and what effects their services have on patient outcomes.

PSMMC introduced its PCAP service in 2012 to expand its pharmaceutical care provision to patient care areas, improve patient care and outcomes, and enhance communication with other healthcare professionals. It also enabled pharmacists to strengthen their involvement in clinical services, in line with PSMMC's strategic goal of becoming the number one place to practice pharmacy in Saudi Arabia.

In the patient-centered model that forms the basis of PSMMC's PCAP service-designed to facilitate creativity and innovative freedompharmacists accept ownership and accountability for both clinical and distributive functions with the aim to enhance the provision of healthcare by reducing mortality rates, medication errors, the length of hospital stay, and costs.

The study revealed that stakeholders are generally accepting of the new pharmacist roles. Study participants agreed that PCAP pharmacists are medication experts with pharmaceutical knowledge and the majority considered that the PCAP system permits pharmacists to change drug treatments when necessary, being aware of alternative medications, as well as to check the appropriateness of the dose and advise on the compatibility, stability, and storage of intravenous drugs. These findings are in line with Gillespie et al [9], who surveyed physicians and nurses working with ward-based pharmacists to evaluate those pharmacists' perceived value. The physicians who participated in that survey found discussing drug therapy with pharmacists to be beneficial, while the participating nurses felt that their own drug therapy knowledge was strengthened by the pharmacists' input and that the pharmacists' treatment recommendations were relevant [9].

The present study also revealed that the majority of the participating stakeholders felt positive about how the pharmacist role had evolved in their healthcare setting. This supports findings from China, the United States, and Indonesia [10-12], however, it differs from the findings of a study conducted in Ethiopia [13], which found that half of the professionals there considered that pharmacists ought to limit their focus to pharmaceuticals and leave patient care to other healthcare providers. The participants in the present study expressed that incorporating PCAP into patient care areas would improve both patient care quality and patient outcomes. They responded positively about their experience of working with pharmacists and recommended expanding the PCAP initiative to cover all wards and specialties. In line with this, a qualitative study of physicians' and nurses' perceptions and expectations of emergency pharmacy units in hospitals located in the city of Kupang, Indonesia, found pharmacists' presence in emergency pharmacy units to have a positive impact not only on both patients and other healthcare staff but also on the speed of patient service delivery [12].

Similarly, a Swedish study reported a majority of participating physicians and nurses to be supportive of the new collaborative involvement of ward-based pharmacists; respondents in that study considered that the quality of both drug therapy and drug-related patient safety had 
increased [9]. Yet another study examined a new care model in which a clinical pharmacist conducted structured medication reviews that then informed the systematic medication care plans devised by a multidisciplinary team. That model was found to be very effective in reducing the number of unidentified drug-related problems (DRPs) in a hospital setting, and the participating physicians and nurses reported valuing the pharmacy services and finding the pharmacists' interventions useful [14].

Moreover, a US study of primary care providers (PCPs) and their perceptions of the impact of clinical pharmacy services on disease state management in primary care revealed a high satisfaction level and that PCPs were largely in favor of collaborating with clinical pharmacists in primary care, particularly as such collaboration did not increase the PCPs' workload [11]. In addition, a study of physicians within a family practice team in Canada reported practice-level benefits after integrating the input of a pharmacist [15]. A systematic review by Kaboli et al. also reported that clinical pharmacists' involvement improved drug treatment quality for in-ward patients with no evidence of harm, as well as increasing the quality, safety, and efficiency of patient care [2]. Finally, Graabaek et al. conducted a mini-review in 2013, finding that clinical pharmacy services have positive effects on medication use, health service use, and costs [16].

\section{Limitations of the study}

The findings in this study were subject to some limitations, the first being that it was a singlecenter survey of stakeholder groups; the second being that it was conducted in only three hospital departments - the NICU, the HDU, and pediatric nephrology; and the third being that it was based on only a small sample size. These limitations mean that the results of the study must be interpreted carefully and that the data cannot be generalized.

\section{CONCLUSION}

This study has provided valuable insight into how physicians, nurses and pharmacists view the PCAP services currently being offered in certain PSMMC patient care areas and highlighted the potential roles for pharmacists practicing within those areas. Although PSMMC PCAP initiative is in its infancy, stakeholders anticipate that integrating pharmacists into patient care areas will likely reduce other healthcare staff's workload, improve the clinical and distributive services, save time and cost, and enhance communication among all healthcare professionals. Although few PSMMC wards have implemented the PCAP model to date, the findings of this study will help support its expansion to all PSMMC patient care areas. For this to happen successfully, PCAP roles, capabilities, and responsibilities must be clearly defined. Future studies should focus on how to expand PCAP service to other PSMMC wards.

\section{DECLARATIONS}

\section{Acknowledgement}

The authors thank all medical and nursing staff in the ICU, HDU, and pediatric nephrology departments for their participation, their commitment, and their high response rate. The authors are also grateful to the Deanship of Scientific Research and RSSU at King Saud University for their technical support.

\section{Conflict of interest}

No conflict of interest is associated with this work.

\section{Contribution of authors}

We declare that this work was done by the authors named in this article and all liabilities pertaining to claims relating to the content of this article will be borne by the authors.

\section{Open Access}

This is an Open Access article that uses a funding model which does not charge readers or their institutions for access and distributed under the terms of the Creative Commons Attribution License (http://creativecommons.org/licenses/by/ 4.0) and the Budapest Open Access Initiative (http://www.budapestopenaccessinitiative.org/rea d), which permit unrestricted use, distribution, and reproduction in any medium, provided the original work is properly credited.

\section{REFERENCES}

1. Auta A, Maz J, Strickland-Hodge B. Perceived facilitators to change in hospital pharmacy practice in England. Int J Clin Pharm. 2015; 37: 1068-1075.

2. Kaboli PJ, Hoth AB, McClimon BJ, Schnipper JL. Clinical pharmacists and inpatient medical care: a systematic review. Arch Intern Med. 2006; 166: 955-964.

3. Dalton K, Byrne $S$. Role of the pharmacist in reducing healthcare costs: current insights. Integr Pharm Res Pract. 2017; 6: 37-46. 
4. Koshman SL, Charrois TL, Simpson SH, McAlister FA, Tsuyuki RT. Pharmacist care of patients with heart failure: a systematic review of randomized trials. Arch Intern Med. 2008; 168: 687-694.

5. Chisholm-Burns MA, Kim Lee J, Spivey CA, Slack M, Herrier RN, Hall-Lipsy E, et al. US pharmacists' effect as team members on patient care: systematic review and meta-analyses. Med Care. 2010; 48: 923-33.

6. Cipolle RJ, Strand LM, Morley PC. Pharmaceutical Care. 2nd Edition: McGraw-Hill, London.; 1998.

7. Declaration of Helsinki. Recommendations Guiding Physicians in Biomedical Research Involving Human Patients. Amended by the 52nd WMA General Assembly, Edinburgh, Scotland; 2000.

8. ICH Harmonized Tripartite Guideline. Guideline for Good Clinical Practice E6 (R1). Geneva: ICH; 1996.

9. Gillespie $U$, Morlin $C$, Hammarlund-Udenaes $M$, Hedstrom M. Perceived value of ward-based pharmacists from the perspective of physicians and nurses. Int J Clin Pharm. 2012; 34: 127-35.

10. Li X, Huo H, Kong W, Li F, Wang J. Physicians' perceptions and attitudes toward clinical pharmacy services in urban general hospitals in China. Int $\mathrm{J}$ Clin Pharm. 2014; 36: 443-50.

11. Truong $H$, Kroehl ME, Lewis $C$, Pettigrew R, Bennett $M$, Saseen $\mathrm{JJ}$, et al. Clinical pharmacists in primary care:
Provider satisfaction and perceived impact on quality of care provided. SAGE Open Med. 2017; 5: 2050312117713911.

12. Safitrih L, Perwitasari DA, Ndoen N, Dandan KL. Health Workers' Perceptions and Expectations of the Role of the Pharmacist in Emergency Units: A Qualitative Study in Kupang, Indonesia. Pharmacy (Basel). 2019; 7.

13. Bilal Al, Tilahun Z, Beedemariam G, Ayalneh B, Hailemeskel B, Engidawork E. Attitude and satisfaction of health care providers towards clinical pharmacy services in Ethiopia: A post-deployment survey. J Pharm Policy Pract. 2016; 9: 7.

14. Bondesson A, Eriksson T, Kragh A, Holmdahl L, Midlov $P$, Hoglund $P$. In-hospital medication reviews reduce unidentified drug-related problems. Eur $J$ Clin Pharmacol. 2013; 69: 647-655.

15. Pottie K, Farrell B, Haydt S, Dolovich L, Sellors C, Kennie $N$, et al. Integrating pharmacists into family practice teams: physicians' perspectives on collaborative care. Can Fam Physician. 2008; 54: 1714-1717 e5.

16. Graabaek T, Kjeldsen LJ. Medication reviews by clinical pharmacists at hospitals lead to improved patient outcomes: a systematic review. Basic Clin Pharmacol Toxicol. 2013; 112: 359-373. 